\title{
Evaluation of Use of Different Local Hemostatic Materials for Closure of the Percutaneous Nephrolithotomy Tract
}

\author{
MOHAMED M. EL-KHASHAB, M.Sc.; AYMAN M. HAGRAS, M.D.; MOHAMED H. RADWAN, M.D. and \\ MOHAMED A. EL-BENDARY, M.D.
}

The Department of Urology, Faculty of Medicine, Tanta University, Al-Gharbia, Egypt

\begin{abstract}
Background: Percutaneous Nephrolithotomy (PCNL) is the preferred technique for treating large stones $>2 \mathrm{~cm}$ in diameter within the kidney, placement of a percutaneous nephrostomy tube for hemostasis, drainage and for second look has been an integral part of the standard PCNL procedure, however the procedure has been modified to tubeless PCNL to decrease hospital stay and analgesic use duration. Many studies advice for the use of adjuvant local hemostatic sealants to decrease both bleeding and extravasation.
\end{abstract}

Objective: Evaluation of local hemostatic sealants used in tubeless PCNL.

Methods: One hundred and fifty patients with renal stone $2-3 \mathrm{~cm}$ in diameter who were enrolled for PCNL were divided into five equal groups; groups from 1 to 4 had tubeless PCNL.

We used Gelatin matrix hemostatic sealant (Surgiflo), collagen sponge coated with thrombin and fibrinogen (Tachosil), oxidized cellulose (Surgicel), gelatin sponge (Gelfoam) in the $1^{\text {st }}, 2^{\text {nd }}, 3^{\text {rd }}$ and $4^{\text {th }}$ respectively while in the $5^{\text {th }}$ group standard PCNL was done.

We compared the groups regarding demographic data, stone site and size, intraoperative time, estimated blood loss (Hematocrit value drop in \% before and after PCNL), postoperative pain, analgesic duration, length of hospital stay, complications, and cost.

Results: Between the five groups, no significant difference concerns the demographic data stone size and site, intraoperative time, estimated blood loss and complications and a significant difference concerning the cost, hospital stay, visual pain analogue scale and analgesic use duration.

Conclusion: The use of local hemostatic sealants is safe and to be considered for cases who underwent tubeless PCNL.

There were no significant differences among the four sealants used in the present study as regard applicability, safety and overall complications post-operatively.

However the Tachosil material is found to be costy when compared to the other materials.

Correspondence to: Dr. Mohamed M. El-Khashab, E-Mail: dr m elkhashab@yahoo.com
Further studies including large group of patients as well as more complex stones are required in the future.

Key Words: Percutaneous nephrolithotomy-Renal stoneTubeless PCNL - hemostatic sealants - Gelatin matrix - Surgiflo - Collagen sponge - Tachosil - Surgicel-Gelatin sponge-Gelfoam.

\section{Introduction}

PERCUTANEOUS Nephrolithotomy (PCNL) is the preferred technique for treating large upper urinary tract stone (over $2 \mathrm{~cm}$ in diameter) [1].

Placement of a percutaneous nephrostomy tube for hemostasis, drainage and for second look has been an integral part of the standard (PCNL) procedure [2].

Recently, there is trend towards tubeless PCNL with a good outcome in selected patients such as stone burden $<3 \mathrm{~cm}$, single tract access, no significant residual stones, no significant perforation, minimal bleeding, and no requirement for a secondary procedure with potential advantages of decreased postoperative pain, analgesia requirement, and hospital stay [3-5].

Due to the development and improvement in lithotripsy technique and new smaller instruments in addition to prolonged experience, the tubeless PCNL limitations have been gradually overcoming [6]

Several studies advocate local hemostatic sealants injected into the tract to decrease both bleeding and urine extravasation, though they have been demonstrated to be safe and effective in enhancing tract closure, the most appropriate agent and technique has yet to be determined [7-10] 


\section{Patients and Methods}

This prospective study included 150 patients who were admitted into Urology Department, Tanta University Hospital suffering from renal stones with stone burden $2-3 \mathrm{~cm}$ and were scheduled for PCNL during the period from June 2016 to December 2017.

Our study was approved by the Local Ethics and Research Committee at Tanta Faculty of Medicine; informed consent was obtained from all participants before enrollment in the study.

The patients were divided into 5 equal groups; groups from 1 to 4 had tubeless PCNL with adjuvant sealant materials.

We used gelatin matrix hemostatic sealant (Surgiflo) (Ethicon Company) (USA), collagen sponge coated with thrombin and fibrinogen (Tachosil) (Baxter company) (Germany), oxidized cellulose (Surgicel) (Ethicon company) (USA), gelatin sponge (Gelfoam) (Pfizer company) (USA) in the 1 st, 2 nd, 3 rd and 4 th respectively while in the 5 th group standard PCNL was done (control group).

Each patient was pre-operatively evaluated with complete history taking, general and local examination, routine laboratory investigations, plain urinary tract film and non-contrast spiral CT scan abdomen and pelvis and pre-operative urinary tract infection was treated with culture specific antibiotic prior to the procedure.

Patients with complete staghorn stone, cases with uncontrolled bleeding disorders, patients with elevated serum creatinine, solitary kidney, and congenital anomalies such as horseshoe kidney were excluded from the study.

Also cases that had a significant calyceal injury, extravasations, bleeding during the procedure or incomplete stone clearance were excluded from the study.

The five groups were compared as regards demographic data, stone site and size, intraoperative time, estimated blood loss (Hematocrit value drop in $\%$ before and after PCNL), post-operative pain, analgesic duration, length of hospital stay, complications, and cost.

\section{Operative procedure:}

A prophylactic single dose of parenteral broadspectrum antibiotic (1gm. Cefepime) was administered to all patients one hour prior to surgery.
Under general anesthesia in lithotomy position, every patient was subjected to cystoscopy with ureteric catheter insertion under c-arm guide for dye injection during kidney puncturing, and then the patient was turned into prone position.

Opacification of the collecting system by contrast media was done and the desired calyx was punctured by 18 gauges Chiba needle (all cases done through infra-costal access and in the prone position).

The proper calyceal puncture was confirmed with free flow of urine through the needle and the wire was placed.

The tract dilatation was achieved by facial dilator up to $12 \mathrm{~F}$ followed by balloon dilatation under fluoroscopic control to 30F, the Amplatz sheath was passed over the inflated balloon; both pneumatic and/or ultrasonic lithotripters were used to break stones into small fragments that were extracted by grasping forceps.

In the first (Surgiflo) group: The surgiflo set contain 2 syringes one is empty and the other contains the hemostatic matrix, $3 \mathrm{mls}$ of sterile saline was drawn by the empty syringe then attach it to the matrix syringe, then mixing them together, once mixed, the empty syringe was removed and the applicator tip was attached to the matrix syringe.

The nephroscope was used to allow visualization of the calyceal-parenchymal junction then we started to inject surgiflo via the sheath during its gradual withdrawal from the tract.

The wire was removed followed by primary skin closure with ureteral stenting as seen in Figs. $(1,2)$.

The second (Tachosil) group: After extraction of the stone fragments, TachoSil sheath was dipped in saline or contrast media (to be inserted under $\mathrm{c}$-arm control) and rolled like cigarette over yellow (active) surface (we used one patch size $9.5 \mathrm{~cm} \mathrm{X}$ $4.8 \mathrm{~cm}$ for each case).

TachoSil sheath then was inserted via Amplatz sheath using forceps and placed into renal parenchymal tract.

The sheath and the wire were removed as seen in Figs. (3-5).

In the third (surgicel snow) group: At the end of the procedure, surgicel (we use 2 patches of 
surgicel snow size 2 inch $\mathrm{x} 4$ inch), was rolled like cigarette and dipped in saline or contrast media (to be inserted under c-arm control) and was inserted via Amplatz sheath then pushed through the Amplatz sheath using forceps or largest facial dilator $28 \mathrm{Fr}$ or $30 \mathrm{Fr}$ in a reverse direction.

Lastly the sheath and the wire were removed as seen in Figs. (6-8).
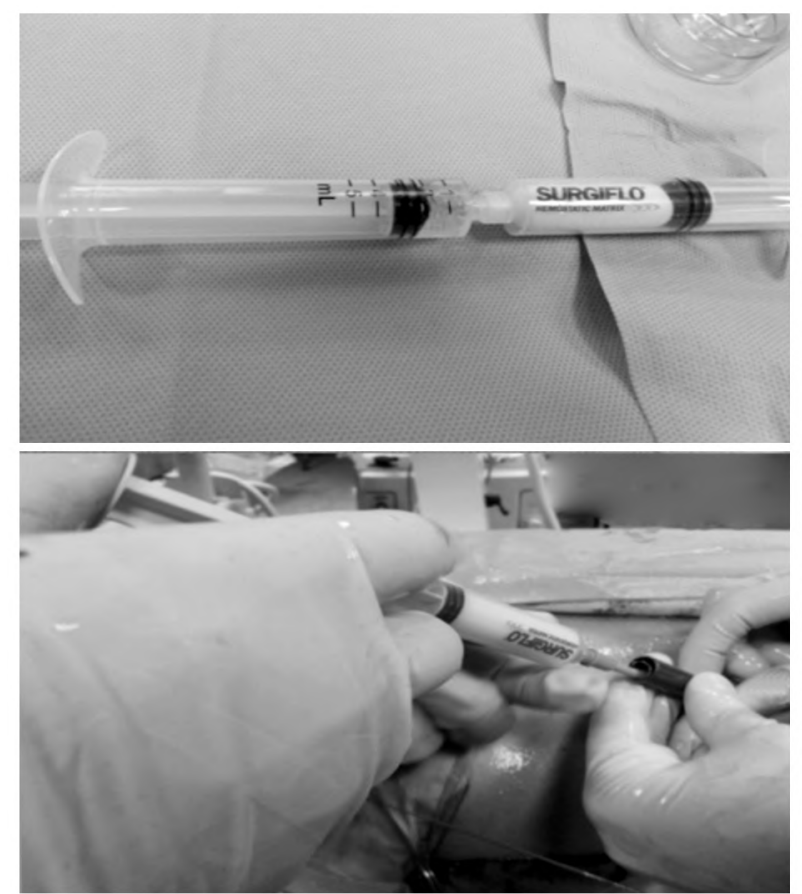

Fig. (1): Surgiflo application.
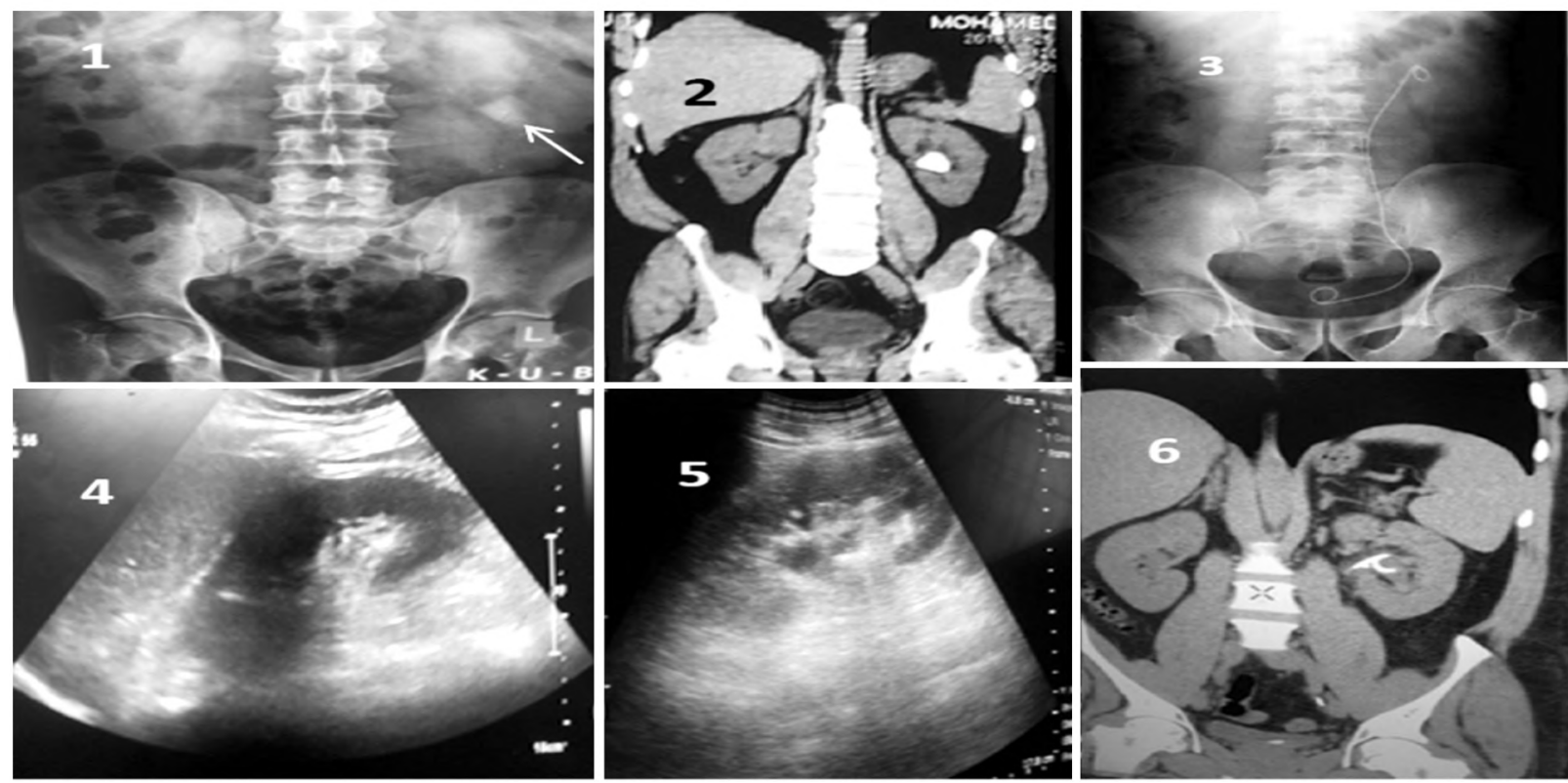

Fig. (2): A case of Surgiflo.

1- Pre-operative KUB.

2- Pre-operative NCCT.

3- Post-operative KUB.

4- Post-operative U/S (1 st day post-operative).

5- Post-operative U/S (1 week post-operative).

6- Post-operative CTU (6 weeks post-operative). 

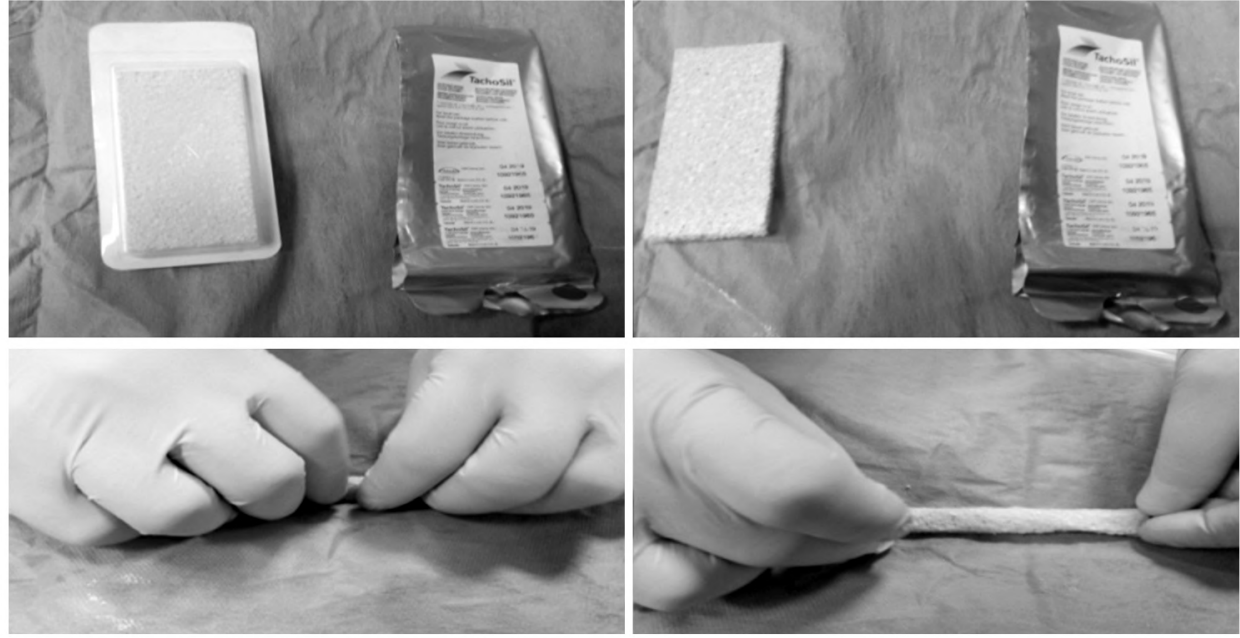

Fig. (3): Method of (Tachosil) preparation.

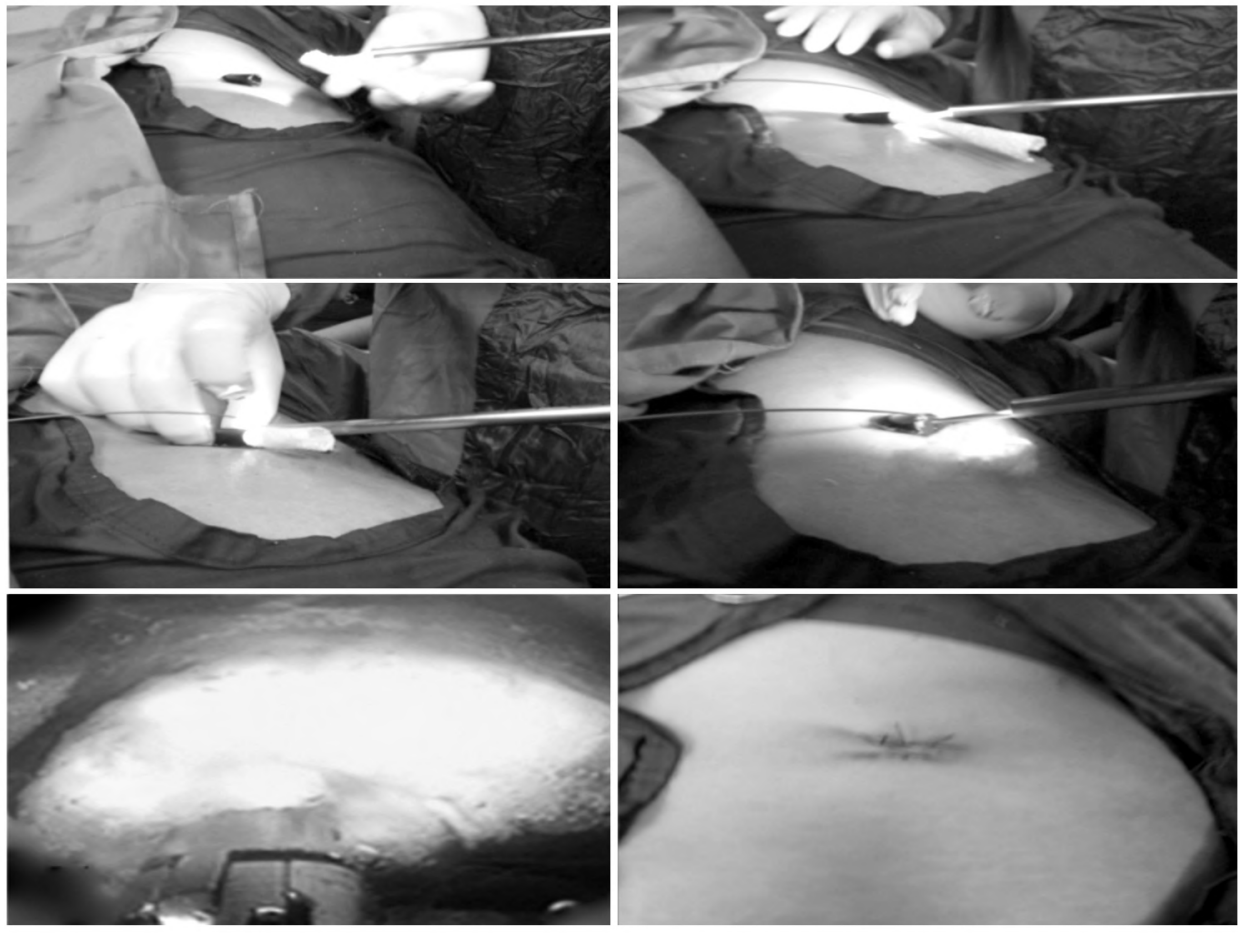

Fig. (4): Method of (Tachosil) insertion.

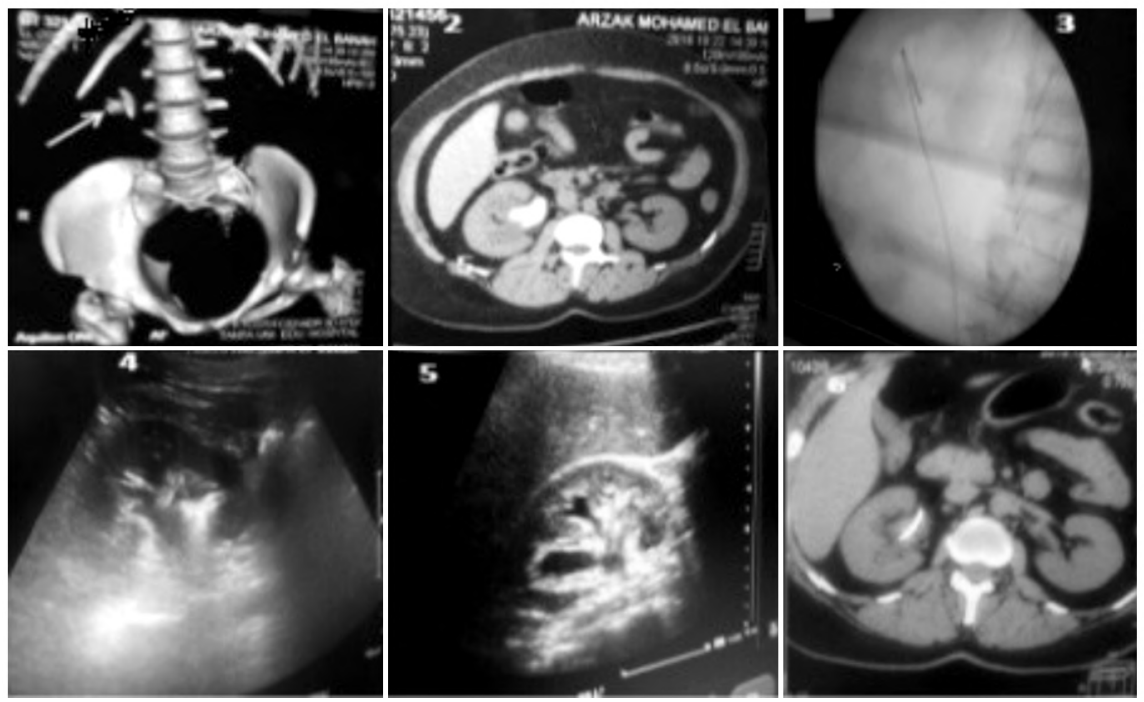

Fig. (5): A case of Tachosil.

1,2- Pre-operative CTU.

3- Post-operative C-arm image.

4- Post-operative U/S (1 st day postoperative).

5- Post-operative U/S (1 week postoperative).

6- Post-operative CTU (6 weeks postoperative). 

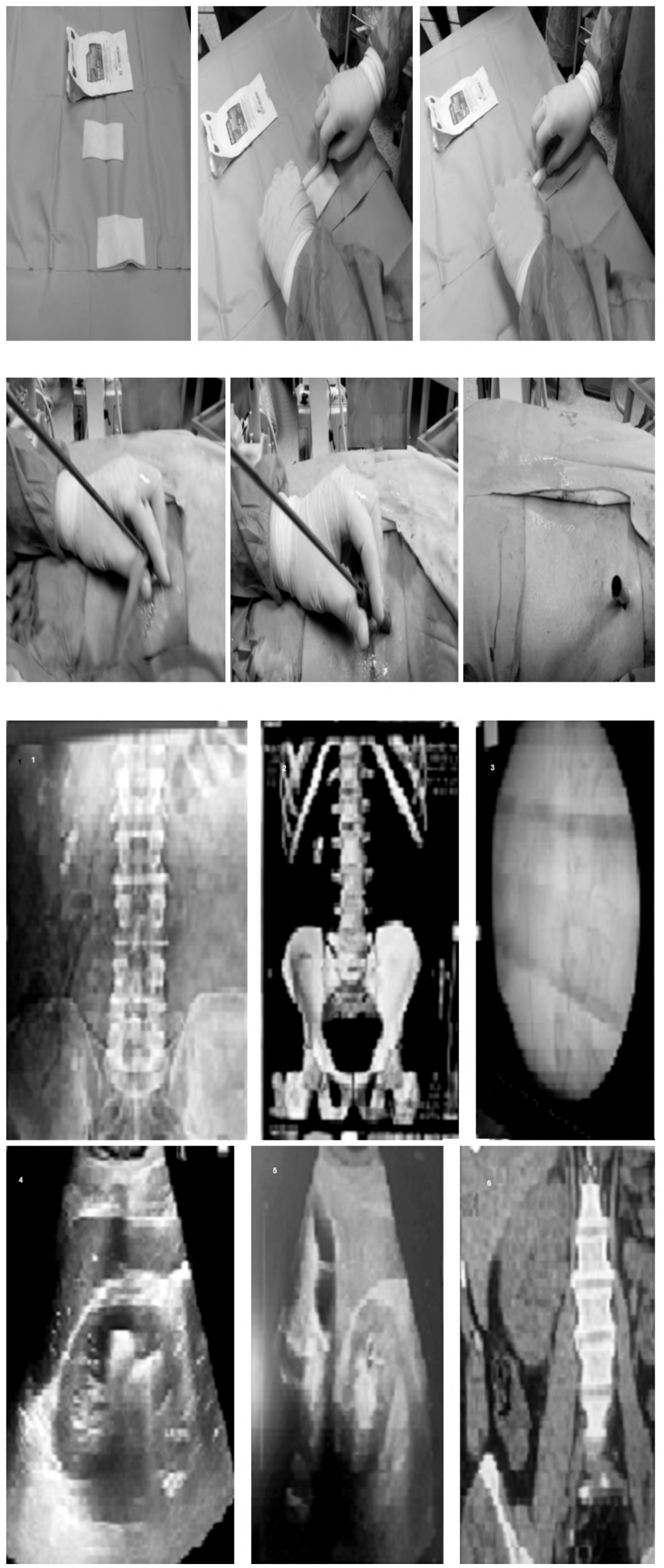

Fig. (6): Surgicel snow preparation.

Fig. (7): Surgicel snow insertion.

Fig. (8): A case of surgicel snow.

1- Pre-operative KUB.

2- Pre-operative CTU.

3- Post-operative C-arm image.

4- Post-operative U/S (1st day postoperative).

5- Post-operative U/S (1 week postoperative).

6- Post-operative CTU (6 weeks postoperative). 


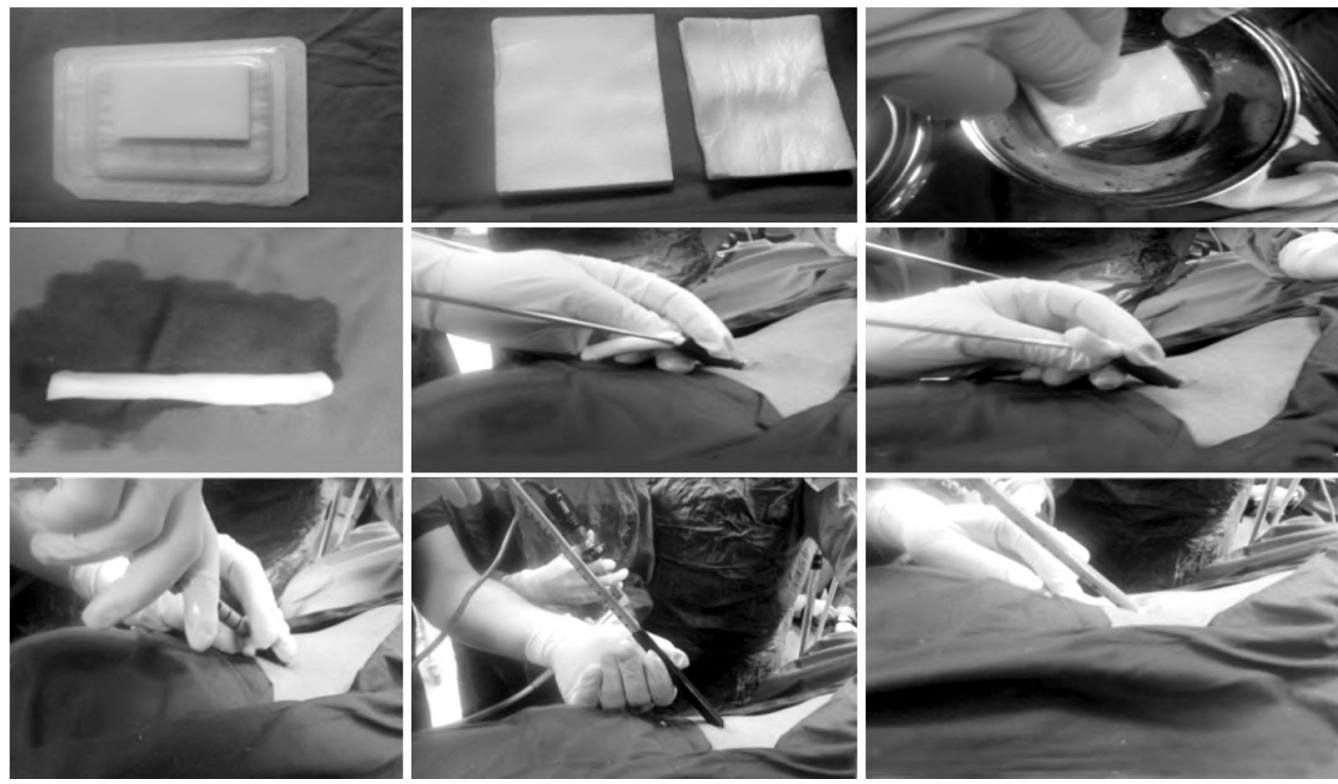

Fig. (9): Method of (gelfoam) application.
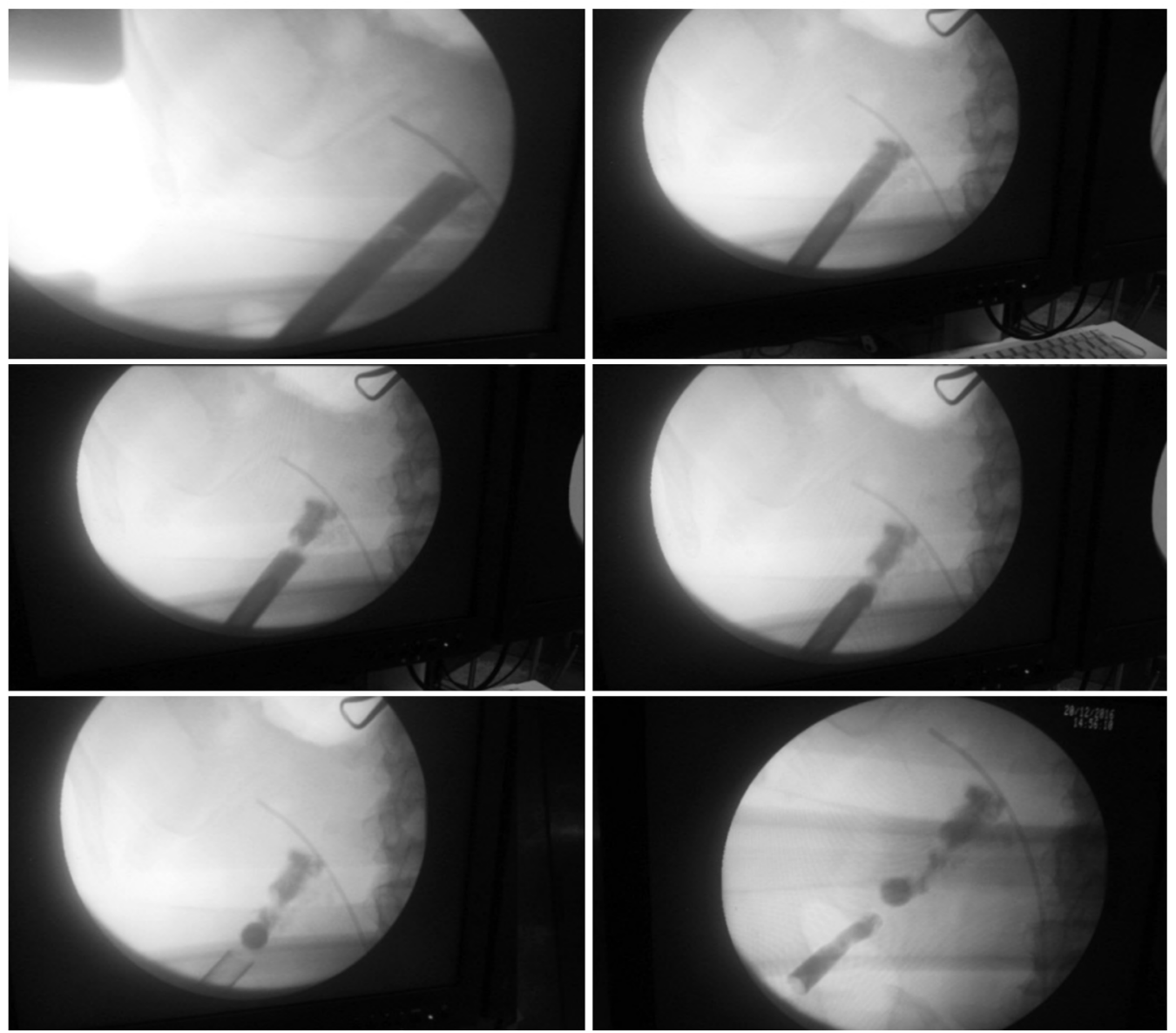

Fig. (10): C-arm image of gelfoam soaked by contrast media. 


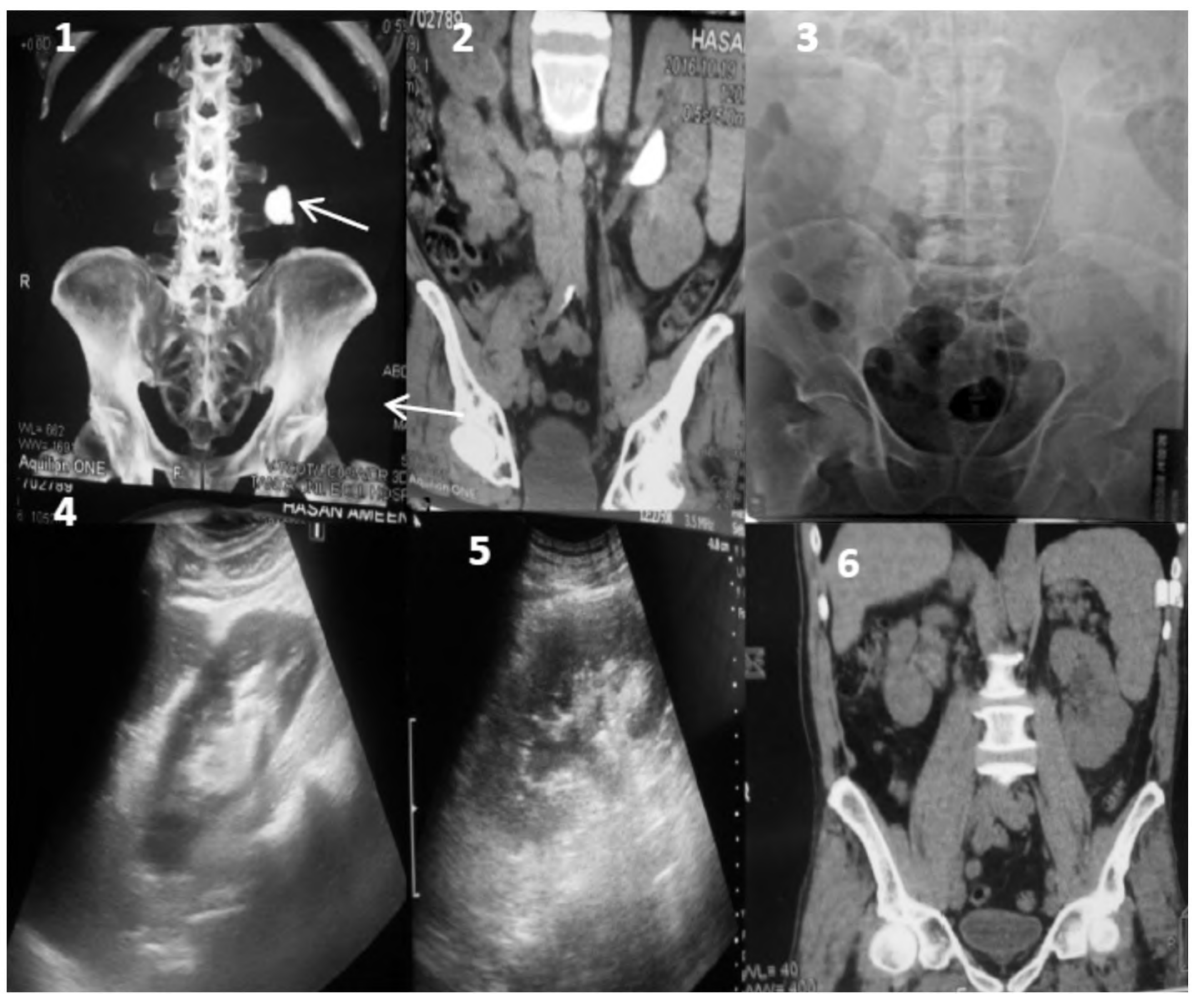

Fig. (11): A case of gelfoam.

1,2- Pre-operative CTU.

3- Post-operative KUB.

4- Post-operative U/S (1 st day post-operative).

5- Post-operative U/S (1 week post-operative)

6- Post-operative CTU (6 weeks post-operative)
In the fifth (nephrostomy tube) group: After satisfactory conclusion of the cases the nephrostomy tube $16 \mathrm{Fr}$ was inserted under c-arm then sheath and the wire was removed then primary skin closure with ureteral stenting this is the standard method of PCNL which done in our department in treating renal stones through the percutaneous nephrolithtomy approach.

Post-operative evaluation: Immediately postoperative, I.V. fluids were administered in the first post-operative day. Vital data were measured. Pain control was achieved (NSAID) and Antibiotic (1gm. Cefepime/12 hour) was administered, hemoglobin and hematocrit levels were done 8 hours after operation, urine output, volume and color were monitored.

Follow-up was done by ultrasound on first day post-operative and after 1 week to assess any perinephric collection, PUT on the 2 nd day postoperatively and NCCT after 6 weeks.

\section{Statistical analysis:}

Statistical analysis was done using IBM SPSS software Version 20.0. (Armonk, NY: IBM Corp). Categorical variables were compared with the chisquared test and numerical variables were compared with ANOVA test. $p<0.05$ was considered statistically significant.

\section{Results}

The total number of cases legible for the study was 150 patients, all patients underwent successful percutaneous nephrolithtomy via single access and the procedure ended with no significant bleeding from the tract or any visible residual stones on the $\mathrm{X}$-ray.

Regarding the demographic data, there were 85 males (56.7\%) and 65 females (43.3\%), the age of the patients ranged from 24 years to 60 years with a mean of $41.5 \pm 9.6$ years and the BMI of the patients ranged from $21 \mathrm{~kg} / \mathrm{m}^{2}$ to $33 \mathrm{~kg} / \mathrm{m}^{2}$ with a mean of $27.4 \pm 3.2 \mathrm{~kg} / \mathrm{m}^{2}$ without a significant difference between five groups as regard sex, age and BMI of patients ( $p$-value $0.58,0.12$ and 0.08 respectively) as seen in (Table 1 ).

Concerning, the radiological data, there were $73(48.7 \%)$ cases with left sided renal stone and $77(51.3 \%)$ cases with right sided renal stones and the mean stone size the mean stone size was $2.6 \pm$ $0.28 \mathrm{~cm}$ with no significant difference between groups ( $p$-value 0.49 and 0.29 respectively) as seen in (Table 2).

Among our groups the intraoperative time ranged from 65 minutes to 105 minutes without a significant difference between groups ( $p$-value 0.51 ) as seen in (Table 3 ). 
The mean blood loss was $2.89 \pm 0.80 \%$ with no significant difference between five groups ( $p$-value 0.18 ) without need for blood transfusion as seen in (Table 4).

Concerning the post-operative pain, the mean visual pain analogue scale of the tubeless groups (1 st four groups) was $2.59 \pm 0.7$ while the control group showed more pain as the mean visual pain analogue scale was $3.9 \pm 1.67$ with significant difference between groups ( $p$-value $<0.001)$ as seen in (Table 5).

In the present study, the mean hospital stay of the tubeless groups was $2.7 \pm 0.67$ days while the control group showed longer hospital stay with a mean of $3.5 \pm 0.66$ days with significant difference between five groups ( $p$-value $<0.001$ ) as seen in (Table 6).

Also the tubeless groups showed lower period of analgesic consumption with a mean of $3.36 \pm 1.02$ days while the control group showed longer period with a mean of $5.3 \pm 1.37$ days with significant difference between groups ( $p$-value $<0.001)$ seen in (Table 7).

There was no difference as regards the difficulty in application of the hemostatic sealants or time needed for application.

The time required for application of any of the four sealants was 1- 2 minutes.

However, the 1 st type required a special applicator (included in the set) to introduce the material into the tract.
All complications in our study were minor according to Clavien-Dindo classification with no significant difference between groups ( $p$-value 0.90 ), also no inflammatory reaction at the skin site of tract was seen at early postoperative visits among the patients of the 1 st four groups as seen in (Table 8).

These complications included a total of 18 cases, 9 cases developed fever all treated conservatively by antipyretic (paracetamol bottle/12h) and antibiotic (cefepime $1 \mathrm{gm} / 12 \mathrm{~h}$ ) except one case that need intervention as this case had slipped ureteric catheter early postoperative and presented by fever with a moderate perinephric collection so DJ fixation was done and managed conservatively.

Also six cases had as a rim of fluid around the lower pole of the kidney and the patients were asymptomatic and this collection disappeared on ultrasonography 1 week later.

Lastly 3 cases in the surgiflo group presented by migration of the injected sealant in the collecting system which diagnosed by ultrasonography, surgiflo disappeared after 6 weeks as proved by NCCT as seen in (Table 8).

Regarding the cost in dollars, there was significant difference in the cost between the four sealants and between the sealants groups and the nephrostomy tube group, the highest cost was the Tachosil sealant as each case of Tachosil costs $300 \$$, the lowest cost was the gelfoam group as each case costs $20 \$$ lastly the price of the nephrostomy tube was $5 \$$ as seen in (Table 9).

Table (1): Demographic data of the five groups.

\begin{tabular}{|c|c|c|c|c|c|c|c|c|c|c|c|c|}
\hline & \multicolumn{2}{|c|}{$\begin{array}{l}1 \text { st group } \\
\text { Surgiflo } \\
(n=30)\end{array}$} & \multicolumn{2}{|c|}{$\begin{array}{c}\text { 2nd group } \\
\text { Tachosil } \\
(n=30)\end{array}$} & \multicolumn{2}{|c|}{$\begin{array}{c}3^{\text {rd }} \text { group } \\
\text { Surgical } \\
(n=30)\end{array}$} & \multicolumn{2}{|c|}{$\begin{array}{l}4^{\text {th }} \text { group } \\
\text { Gelfoam } \\
(n=30)\end{array}$} & \multicolumn{2}{|c|}{$\begin{array}{c}\text { 5th group } \\
\text { Control } \\
\text { group }(n=30)\end{array}$} & \multirow{2}{*}{$\begin{array}{c}\text { Test } \\
\text { of } \\
\text { Sig. }\end{array}$} & \multirow[t]{2}{*}{$p$} \\
\hline & No. & $\%$ & No. & $\%$ & No. & $\%$ & No. & $\%$ & No. & $\%$ & & \\
\hline \multicolumn{13}{|l|}{ Sex: } \\
\hline Male & 17 & 56.7 & 18 & 60 & 15 & 50 & 19 & 63.3 & 16 & 53.3 & $\chi^{2}=$ & $p=$ \\
\hline Female & 13 & 43.3 & 12 & 40 & 15 & 50 & 11 & 36.7 & 14 & 46.7 & 1.357 & 0.852 \\
\hline \multicolumn{13}{|l|}{ Age (years): } \\
\hline Min.-max. & \multicolumn{2}{|c|}{$30.0-60.0$} & \multicolumn{2}{|c|}{$32.0-54.0$} & \multicolumn{2}{|c|}{$29.0-58.0$} & \multicolumn{2}{|c|}{$24.0-60.0$} & \multicolumn{2}{|c|}{$24.0-55.0$} & $\mathrm{~F}=$ & $p=$ \\
\hline Mean \pm SD & \multicolumn{2}{|c|}{$44.1 \pm 10.02$} & \multicolumn{2}{|c|}{$7.04 \pm 42.6$} & \multicolumn{2}{|c|}{$8.65 \pm 43$} & \multicolumn{2}{|c|}{$11.5 \pm 39.1$} & \multicolumn{2}{|c|}{$38.9 \pm 9.94$} & 1.86 & 0.12 \\
\hline Median & \multicolumn{2}{|c|}{42} & \multicolumn{2}{|c|}{42} & \multicolumn{2}{|c|}{42.5} & \multicolumn{2}{|c|}{38.5} & \multicolumn{2}{|c|}{37.5} & & \\
\hline \multicolumn{13}{|l|}{$B M I\left(K g / m^{2}\right):$} \\
\hline Min.-max. & \multicolumn{2}{|c|}{$21.0-30.0$} & \multicolumn{2}{|c|}{$23.0-30.0$} & \multicolumn{2}{|c|}{$24.0-33.0$} & \multicolumn{2}{|c|}{$21.0-33.0$} & \multicolumn{2}{|c|}{$21.0-33.0$} & $\mathrm{~F}=$ & $p=$ \\
\hline Mean \pm SD & \multicolumn{2}{|c|}{$2.67 \pm 26.9$} & \multicolumn{2}{|c|}{$2.03 \pm 26.7$} & \multicolumn{2}{|c|}{$2.76 \pm 28.8$} & \multicolumn{2}{|c|}{$4.1 \pm 27.5$} & \multicolumn{2}{|c|}{$27.3 \pm 3.7$} & 2.1 & 0.08 \\
\hline Median & \multicolumn{2}{|c|}{27} & 26.5 & & 29 & & 28. & & 26 & & & \\
\hline
\end{tabular}


Table (2): Stone site and size of the five groups.

\begin{tabular}{|c|c|c|c|c|c|c|c|c|c|c|c|c|}
\hline \multirow[t]{2}{*}{ Stone } & \multicolumn{2}{|c|}{$\begin{array}{l}1 \text { st group } \\
\text { Surgiflo } \\
(n=30)\end{array}$} & \multicolumn{2}{|c|}{$\begin{array}{c}\text { 2nd group } \\
\text { Tachosil } \\
(\mathrm{n}=30)\end{array}$} & \multicolumn{2}{|c|}{$\begin{array}{c}3 \text { rd group } \\
\text { Surgical } \\
(n=30)\end{array}$} & \multicolumn{2}{|c|}{$\begin{array}{l}4 \text { th group } \\
\text { Gelfoam } \\
(n=30)\end{array}$} & \multicolumn{2}{|c|}{$\begin{array}{l}5 \text { th group } \\
\text { Control } \\
(n=30)\end{array}$} & \multirow{2}{*}{$\begin{array}{l}\text { Test } \\
\text { of } \\
\text { Sig. }\end{array}$} & \multirow[t]{2}{*}{$p$} \\
\hline & No. & $\%$ & No. & $\%$ & No. & $\%$ & No. & $\%$ & No. & $\%$ & & \\
\hline \multicolumn{13}{|l|}{ Site: } \\
\hline Right & 15 & 50 & 19 & 63.3 & 15 & 50 & 12 & 40 & 16 & 53.3 & $\chi^{2}=$ & $p=$ \\
\hline Left & 15 & 50 & 11 & 36.7 & 15 & 50 & 18 & 60 & 14 & 46.7 & 3.362 & 0.499 \\
\hline \multicolumn{13}{|l|}{ Size: } \\
\hline Min.-max. & \multicolumn{2}{|c|}{$2.4-3.0$} & \multicolumn{2}{|c|}{$2.2-3.0$} & \multicolumn{2}{|c|}{$2.1-3.0$} & \multicolumn{2}{|c|}{$2.2-3.0$} & \multicolumn{2}{|c|}{$2.2-3.0$} & $\mathrm{~F}=$ & $p=$ \\
\hline Mean \pm SD & \multicolumn{2}{|c|}{$2.71 \pm 0.23$} & \multicolumn{2}{|c|}{$2.6 \pm 0.29$} & \multicolumn{2}{|c|}{$2.55 \pm 0.32$} & \multicolumn{2}{|c|}{$2.59 \pm 0.28$} & \multicolumn{2}{|c|}{$2.58 \pm 0.24$} & 1.424 & 0.299 \\
\hline Median & \multicolumn{2}{|c|}{2.75} & \multicolumn{2}{|c|}{2.6} & \multicolumn{2}{|c|}{2.55} & \multicolumn{2}{|c|}{2.55} & \multicolumn{2}{|c|}{2.55} & & \\
\hline
\end{tabular}

Table (3): Intraoperative time of the five groups.

\begin{tabular}{|c|c|c|c|c|c|c|c|}
\hline $\begin{array}{l}\text { Operative } \\
\text { time } \\
\text { (in minutes) }\end{array}$ & $\begin{array}{l}1 \text { st group } \\
\text { Surgiflo } \\
(\mathrm{n}=30)\end{array}$ & $\begin{array}{c}\text { 2nd group } \\
\text { Tachosil } \\
(\mathrm{n}=30)\end{array}$ & $\begin{array}{l}3^{\text {rd }} \text { group } \\
\text { Surgical } \\
(\mathrm{n}=30)\end{array}$ & $\begin{array}{l}\text { 4th group } \\
\text { Gelfoam } \\
(\mathrm{n}=30)\end{array}$ & $\begin{array}{l}\text { 5th group } \\
\text { Control } \\
(\mathrm{n}=30)\end{array}$ & $\begin{array}{l}\text { Test } \\
\text { of } \\
\text { Sig. }\end{array}$ & $p$ \\
\hline Min.-max. & $65-96 \mathrm{~min}$ & $65-103 \min$ & $67-105 \mathrm{~min}$ & $65-105 \min$ & $65-100 \mathrm{~min}$ & $\mathrm{~F}=$ & $p=$ \\
\hline $\begin{array}{l}\text { Mean } \pm \text { SD. } \\
\text { Median }\end{array}$ & $\begin{array}{l}9.4 \pm 87.9 \mathrm{~min} . \\
70 \mathrm{~min} .\end{array}$ & $\begin{array}{l}11.4 \pm 79.5 \mathrm{~min} . \\
73 \mathrm{~min} .\end{array}$ & $\begin{array}{l}80.3 \pm 13.2 \mathrm{~min} . \\
79 \mathrm{~min} .\end{array}$ & $\begin{array}{l}84 \pm 12.4 \mathrm{~min} \\
82 \mathrm{~min} .\end{array}$ & $\begin{array}{l}80.3 \pm 13.3 \mathrm{~min} . \\
80 \mathrm{~min} .\end{array}$ & 0.823 & 0.512 \\
\hline
\end{tabular}

Table (4): Estimated blood loss of the five groups.

\begin{tabular}{|c|c|c|c|c|c|c|c|}
\hline & $\begin{array}{c}1 \text { st group } \\
\text { Surgiflo } \\
(n=30)\end{array}$ & $\begin{array}{c}\text { 2nd group } \\
\text { Tachosil } \\
(n=30)\end{array}$ & $\begin{array}{c}3^{\text {rd }} \text { group } \\
\text { Surgical } \\
(n=30)\end{array}$ & $\begin{array}{c}\text { 4th group } \\
\text { Gelfoam } \\
(n=30)\end{array}$ & $\begin{array}{l}\text { 5th group } \\
\text { Control } \\
(\mathrm{n}=30)\end{array}$ & $\begin{array}{l}\text { Test } \\
\text { of } \\
\text { Sig. }\end{array}$ & $p$ \\
\hline Min.-max. & $1 \%-4 \%$ & $2 \%-5 \%$ & $2 \%-4 \%$ & $2 \%-4 \%$ & $2 \%-4 \%$ & $\mathrm{~F}=$ & $p=$ \\
\hline Mean \pm SD. & $0.8 \pm 2.67$ & $0.91 \pm 3.17$ & $0.75 \pm 2.83$ & $0.74 \pm 2.93$ & $0.77 \pm 2.84$ & 1.58 & 0.18 \\
\hline Median & 3 & 3 & 3 & 3 & 3 & & \\
\hline
\end{tabular}

Table (5): Visual pain analogue scale.

Table (6): Length of hospital stay (in days) of the five groups.

\begin{tabular}{|c|c|c|c|c|c|c|c|}
\hline Variable & Mean \pm SD & & $p$ & Variable & Mean \pm SD & & $p$ \\
\hline Visual pain analogue scale: & & \multirow{6}{*}{$\begin{array}{l}\mathrm{F}= \\
1.58\end{array}$} & \multirow{6}{*}{$<0.001$} & Hospital stay (in days): & & \multirow{6}{*}{$\begin{array}{l}\mathrm{F}= \\
9.88\end{array}$} & \multirow{6}{*}{$<0.001$} \\
\hline Surgiflo group & $2.3 \pm 0.45$ & & & Surgiflo group & $2.78 \pm 0.467$ & & \\
\hline Tachosil group & $2.5 \pm 0.51$ & & & Tachosil group & $2.8 \pm 0.826$ & & \\
\hline Surgicel snow group & $2.8 \pm 0.76$ & & & Surgicel snow group & $2.65 \pm 0.756$ & & \\
\hline Gelfoam group & $2.8 \pm 0.89$ & & & Gelfoam group & $2.6 \pm 0.593$ & & \\
\hline Control group & $3.9 \pm 1.67$ & & & Control group & $3.5 \pm 0.661$ & & \\
\hline
\end{tabular}

Table (7): Duration of analgesic use.

\begin{tabular}{llll}
\hline Variable & Mean \pm SD & & $p$ \\
\hline Duration of analgesic use (in days): & & & \\
$\quad$ Surgiflo group & $3.2 \pm 1.14$ & $\mathrm{~F}=$ & $<0.001$ \\
Tachosil group & $3.4 \pm 1.03$ & 18.17 & \\
Surgicel snow group & $3.4 \pm 0.93$ & & \\
Gelfoam group & $3.4 \pm 1.03$ & & \\
Control group & $5.3 \pm 1.37$ & & \\
\hline
\end{tabular}


Table (8): Complications summary of the five groups.

\begin{tabular}{|c|c|c|c|c|}
\hline Group & $\begin{array}{l}\text { Number of } \\
\text { complicated } \\
\text { cases }\end{array}$ & Complications & & $p$ \\
\hline Surgiflo group & 5 cases & $\begin{array}{l}\text { - } 3 \text { cases: Surgiflo migrated in the pelvicalyceal system. } \\
\text { - One case: Fever. } \\
\text { - One case: Small perinephric collection. }\end{array}$ & $\begin{array}{l}\chi^{2}= \\
1.01\end{array}$ & 0.908 \\
\hline Tachosil group & 4 cases & $\begin{array}{l}\text { - } 2 \text { cases presented by fever. } \\
\text { - } 2 \text { cases: Small perinephric collection. }\end{array}$ & & \\
\hline Surgicel snow group & 3 case & $\begin{array}{l}\text { - } 1 \text { st case developed fever and moderate perinephric collection due to early } \\
\text { post-operative slippage of the ureteric catheter early a DJ stent was placed. } \\
\text { - } 2 \text { cases: Small perinephric collection. }\end{array}$ & & \\
\hline Gelfoam group & 3 cases & $\begin{array}{l}\text { - } 2 \text { cases presented by fever. } \\
\text { - } 1 \text { case presented by a rim of perinephric collection. }\end{array}$ & & \\
\hline Control group & 3 cases & - 3 cases presented by fever. & & \\
\hline
\end{tabular}

Table (9): Cost for each case (in dollars) of the five groups.

\begin{tabular}{llll}
\hline Variable & & $p$ \\
\hline Cost for each case (in dollars): & & & \\
One case of Surgiflo & $200 \$(>100 \$)$ & $\chi^{2}=$ & $<0.001$ \\
One case of Tachosil & $300 \$(>100 \$)$ & 150.000 & \\
One case of Surgicel snow & $180 \$(>100 \$)$ & & \\
One case of gelfoam & $20 \$(<100 \$)$ & & \\
One case of the control group & $5 \$(<100 \$)$ & & \\
\hline
\end{tabular}

\section{Discussion}

PCNL is considered the standard treatment of choice for renal stone more than $2-\mathrm{cm}$ in size.

The procedure is effective, safe and is associated with high stone free rate as well as lower overall complication rate [11]

For the optimum closure for percutaneous tracts, many studies advocate the utilization of local hemostatic sealants injected into the tract to decrease both bleeding and urine extravasation with no definite conclusions [7-10] .

So we designed our prospective study to evaluate the efficacy of different local hemostatic materials used for closure of the PCNL tract.

We studied the safety and complications to determine the most appropriate agent among the studied groups.

Also the cost was getting special attention in the present study.

The patients demographic data were homogenous with no significant difference between groups as regard sex, age and BMI ( $p$-value $0.58,0.12$ and 0.08 respectively), in addition, the pre-operative stone data regarding site, size were also comparable
( $p$-value 0.49 and 0.29 respectively), similarly, the difference in operative time, between the five groups was not statistically significant, also the mean blood loss of the five groups was $3.09 \pm 1.38$ with no significant difference ( $p$-value 0.18 ) without need for blood transfusion.

Overall, the main advantages of tubeless PCNL over the standard PCNL are the short hospital stay, less post-operative pain and analgesic use duration that proved in many studies [7,12-15].

A recent study done by Sreedhar et al., on 40 cases, they divided them into 2 equal groups, $1 \mathrm{st}$ group underwent tubeless PCNL and the 2 nd group underwent standard PCNL, they found that tubeless group has less postoperative hospital stay $(3.5 \pm 0.8$ days), less visual analogue pain scale $(2.3 \pm 0.5)$ and less analgesic duration (2.6 \pm 0.5 days $)$ in comparison with standard PCNL which showed longer hospital stay $(5.0 \pm 0.5)$, high visual analogue pain scale $(3.7 \pm 1.1)$ and analgesic use duration $(4.4 \pm 0.9)$ [16] .

In the present study, the tubeless groups show less post-operative hospital stay with a mean of ( $2.7 \pm 0.67$ days) compared with standard PCNL which was higher $(3.5 \pm 0.66$ days) ( $p$-value $<0.001)$, less post-operative pain which measured by visual analogue pain scale (with a mean of $2.59 \pm 0.7$ in 
tubeless groups compared with standard PCNL which was higher $(3.9 \pm 1.67)(p$-value $<0.001)$.

Also, the duration of post-operative analgesic use consumption was significantly less among tubeless groups (a mean of 3.36 \pm 1.02 days) in comparison with the standard PCNL group (a mean of $5.3 \pm 1.37$ days) ( $p$-value $<0.001)$ which were comparable with the previous study done by Sreedhar et al.

All complications in our study were minor according to Clavien-Dindo classification with no significant difference between groups ( $p$-value $0.90)$.

Also there was no inflammatory reaction at the skin site of tract was seen in any patients during early post-operative visits.

The use of gelatin matrix products (FloSeal and CoSeal synthetic from Baxter, Surgiflo from Johnson \& Johnson) has been studied for closure of the PCNL tract, these materials provide a matrix for platelet adhesion and aggregation, which aid in clot formation, furthermore, the gelatin materials will swell in the tract from 19 to $400 \%$ greater than its volume, adding to hemostasis by the compressive effect $[\mathbf{1 7 , 1 8}$.

Lee et al., in their pilot study (included only 2 patients) proved that injection of gelatin matrix hemostatic sealant (FloSeal Baxter Medical, Fremont, California) into the nephrostomy tract may be of value in preventing bleeding after PCNL [18]

Another study done by JF Borin et al., they described the technique of administration of a hemostatic gelatin matrix (FloSeal; Baxter Inc., Irvine, CA) into the nephrostomy tract and concluded that the use of hemostatic gelatin matrix might achieve immediate hemostasis and avoid the use of a nephrostomy tube with no urinary obstruction from hemostatic sealants [19].

Also, Lan, Chi Yun et al., compared standard PCNL with tubeless PCNL using gelatin matrix as a sealant (Floseal; Baxter, Deerfield, IL, USA), 41 received tubeless PCNL with gelatin matrix as a sealant, they concluded that tubeless PCNL with adjunct use of a gelatin matrix hemostatic sealant can be considered as a safe treatment option for renal calculi with favorable outcome without an increase in complications compared with standard PCNL [12].

Our results in the surgiflo group were found to be comparable to Lan, Chi Yun et al., concerning complications which were minor too, these complications included a total of 5 cases.

In three cases migration of the injected sealant in the collecting system was occurred which diagnosed by ultrasonography post-operatively which disappeared after 6 weeks as proved by NCCT.

Another case developed fever early postoperative which was controlled by antipyretic (paracetamol infusion/12 hour for 3 days) together with the standard post-operative antibiotic (cefepime 1gm./ 12h).

The last patient had perinephric collection diagnosed by ultrasonography as a rim of fluid around the lower pole of the kidney and the patient was asymptomatic, the patient was under watchful waiting and the collection was followed by daily ultrasoungraphy which proved total disappearance of the collection one week later.

Generally, the fibrin sealant (Tachosil) has unique properties as a hemostatic agent, tissue adhesive and urinary tract sealant, make it an attractive adjunct for managing complex surgical problems of the genitourinary tract effectively [20]

Noller et al., used a fibrin sealant (HEMASEEL APR Haemacure Corp.,Sarasota, Florida) after PCNL in eight patients and found it safe and feasible in sealing the renal parenchymal defect with no patients were found to have complications due to administration of fibrin sealant or evidence of fibrin along the PCNL tract [13]

Another recent prospective randomized study was done by Cormio et al., compared standard PCNL with tubeless PCNL using tachosil as a sealant.

The study included a total of 100 patients divided into two equal groups, group (1) received nephrostomy after PCNL and group (2) tubeless PCNL with tachosil as a sealant, they concluded that tachoSil sealed tubeless PCNL had a significant reduction in urinary leakage and bleeding as group (1) showed more urinary leakage that reach significant difference.

Also some cases in group (1) complicated by perirenal hematoma but did not reach statistical significance [21].

Our results as regard complications is comparable to Noller et al., and Cormio et al., except for hematocrit drop post-operatively which was higher in our study $3.17 \pm 0.91 \%$ than in Noller et al., study 
which was $2.8 \%$, however, there was no need for blood transfusion among our cases.

Among our patients in the tachosil group, a total of 4 patients developed complications.

Two cases developed fever and diagnosed with chest infection that controlled by IV antibiotics.

The other 2 cases had perinephric collection diagnosed by ultrasonography as a rim of fluid around the lower pole of the kidney and the patients were asymptomatic, the two cases were under watchful waiting with daily follow-up by ultrasoungraphy which proved complete disappearance of the collection one week later.

Surgicel (oxidized cellulose) has been used for hemostasis for a long time, and its safety and effectiveness had been proved.

It is found to be more cost-effective than alternative sealants, and its use is easier [22].

Yeong-Chin Jou et al., in their study about the contributive factors of fever after tubeless PCNL using surgicel (Surgicel, Johnson \& Johnson, Somerville, NJ) as sealant to facilitate bleeding control, found that sealing the access tract with oxidized degenerated cellulose (surgicel) did not increase the febrile rate after tubeless PCNL [23].

In the present study among patients with surgicel, one patient presented by fever and moderate perinephric collection.

This patient had slipped ureteric catheter early post-operative and a DJ stent was placed.

Another two cases had perinephric collection diagnosed by ultrasonography as a rim of fluid around the lower pole of the kidney and the patients were asymptomatic and managed conservatively with daily follow-up ultrasonography with total disappearance of the collection 1 week later.

However, in the study carried out by Aghamir et al., which was done on 20 patients divided them into 2 equal groups the nephrostomy tracts were sealed with Surgicel (Ethicone $\left.{ }^{\circledR}\right)$ in one group and left unsealed in the other group, they found that the surgicel has no role as a sealant in tubeless PCNL as it did not decrease bleeding or extravasation from the tract.

The authors suggested further studies including large sample size to negate or prove their conclusion [24].
In the 4 th group we used gelfoam as a sealant for closure of the PCNL tract.

Gelfoam is capable of absorbing and holding up to 45 times its weight in blood or other fluids with a supportive and mechanical mechanism of action.

Once gelfoam comes in contact with a bleeding surface, it stops bleeding by producing a mechanical matrix that facilitates clotting [25]

In 2006, a pilot study was done by Schick V et al., included 7 patients with medium stone burden and use gelatin sponge (Spongostan, Johnson \& Johnson), they concluded that gelatin sponge is very reliable and cause immediate hemostasis when used as a sealant after tubeless PCNL [7] .

In the same year, $\mathrm{Yu}$ and Dah-Shyong compared tubeless PCNL with gelatin sponge (Gelfoam, Pharmacia \& Upjohn, Kalamazoo, MI, USA) as a sealant with standard PCNL.

Their study was conducted on 30 patients divided into 2 equal groups.

Among patients in the tubeless PCNL group, there were no severe complications related to the gelatin packing.

They concluded that gelatin sealant packing is an alternative, available, and feasible method for preventing bleeding and urine leakage postoperatively in selected patients receiving tubeless PCNL [14]

Three years later, Singh et al., studied the efficacy and safety of totally tubeless PCNL using absorbable gelatin sponge (Spongostan, Johnson \& Johnson) as an adjunct, on 45 patients with median stone size $3 \mathrm{~cm}$ underwent totally tubeless PCNL, their results showed that the drop in mean hematocrit value was $2.4 \%$ without need for blood transfusion.

In their study a total of 3 cases had perinephric collections and were managed conservatively.

They concluded that percutaneous tract sealing with rolled up absorbable gelatin sponge is simple, cheaper, safe and effective method to manage the acute nephrostomy tract after tubeless PCNL [15]

In the present study the gelatin sponge prepared by adding contrast media and placed in the tract under c-arm guidance was used. 
In this group the complications were minor too, did not reach statistical significance ( $p$-value 0.90 ) when compared with the other groups. $0.74 \%$.

The mean post-operative HCT drop was $2.93 \pm$

Two patients in this group developed fever early post-operatively, in spite of prophylactic antibiotics.

The reason for this is suggested to be the disintegration of the infected stones and the patients treated conservatively by antipyretics (paracetamol bottle/12h) and antibiotic (cefepime 1gm./12h).

Another patient had perinephric collection diagnosed by ultrasonography as a rim of fluid around the lower pole of the kidney which disappeared on ultrasonography 1 week later.

Our results were found to be comparable with Schick V et al., Yu and Dah-Shyong and Singh et al.

In the fifth group 3 cases developed fever early post-operatively and treated conservatively by antipyretics (paracetamol bottle/12h) and antibiotic (cefepime $1 \mathrm{gm} . / 12 \mathrm{~h}$ ).

In general, the cost of topical hemostats is highly variable from country to country and between each type, the intraoperative use of topical hemostats may reduce the need of transfusion of blood products so reduce the duration of hospital stay and reduce the need for analgesia [26]

Now the recent hospitals policy is implementing the move toward bloodless surgery to improve both outcomes and safety, so the use of local hemostatic sealants will increase in the next years [27-29].

Regarding the cost in dollars, there was significant difference in the cost between the four sealants and between the sealants groups and the nephrostomy tube group, the highest cost was the Tachosil sealant as each case of Tachosil costs $300 \$$, the lowest cost was the gelfoam group as each case costs $20 \$$.

\section{Conclusion:}

The use of local hemostatic sealants is safe and to be considered for cases who underwent tubeless PCNL.

There were no significant differences among the four sealants used in the present study as regard applicability, safety and overall complications postoperatively.

However the Tachosil material is found to be costy when compared to the other materials.

Further studies including large group of patients as well as more complex stones are required in the future.

\section{References}

1- KIM B.S.: Recent advancement or less invasive treatment of percutaneous nephrolithotomy. Korean J. Urol., 56 (9): 614-23, 2015

2- MISHRA S., SABNIS R.B., KURIEN A., GANPULE A. MUTHU V. and DESAI M.: Questioning the wisdom of tubeless percutaneous nephrolithotomy (PCNL): A prospective randomized controlled study of early tube removal vs tubeless PCNL. B.J.U. International, 106 (7): 1045-9, 2010 .

3- BELLMAN G.C., DAVIDOFF R., CANDELA J., GERSPACH J., KURTZ S. and STOUT L.: Tubeless percutaneous renal surgery. J. Urol., 157 (5): 1578-82, 1997.

4- FENG M.I., TAMADDON K., MIKHAIL A., KAPTEIN J.S. and BELLMAN G.C.: Prospective randomized study of various techniques of percutaneous nephrolithotomy. Urology, 58 (3): 345-50, 2001.

5- AGRAWAL M.S. and AGRAWAL M.: Tubeless percutaneous nephrolithotomy. I.J.U., 26 (1): 16, 2010.

6- SHAH H.N., SODHA H.S., KHANDKAR A.A., KHARODAWALA S., HEGDE S.S. and BANSAL M.B.: A randomized trial evaluating type of nephrostomy drainage after percutaneous nephrolithotomy: Small bore v tubeless. J. Endourol., 22 (7): 1433-40, 2008.

7- SCHICK V.: Sealing of percutaneous nephrolithotomy access after complete stone removal with a hemostyptic gelatin powder (Spongostan). Aktuelle Urol., 37 (1): 527, 2006.

8- NAGELE U., SCHILLING D., ANASTASIADIS A.G., CORVIN S., SEIBOLD J., KUCZYK M., et al.: Closing the tract of mini-percutaneous nephrolithotomy with gelatine matrix hemostatic sealant can replace nephrostomy tube placement. Urology, 68 (3): 489-93, 2006.

9- CHOE C.H., L'ESPERANCE J.O. and AUGE B.K.: The use of adjunctive hemostatic agents for tubeless percutaneous nephrolithotomy. J. Endourol., 23 (10): 1733-8, 2009 .

10- CHUNG H.S., JUNG S.I., YU H.S., HWANG E.C., OH K.J., KWON D.D., et al.: Modified totally tubeless per cutaneous nephrolithotomy: Is it an effective and safe treatment option for renal and upper ureteral stones? Videosurgery Miniinv., 11 (4): 240, 2016.

11- GOEL A. and HEMAL A.: Evaluation of role of retroperitoneoscopic pyelolithotomy and its comparison with percutaneous nephrolithotripsy. Int. Urol. Nephrol., 35 (1): 73-6, 2003

12- LAN C.Y., TZOU K.Y., HU S.W., HO C.H., TE CHIANG Y., WU C.C., et al.: Use of hemostatic sealant in tubeless 
percutaneous nephrolithotomy: Experience of a single institution from Taiwan. Jurols, 28 (2): 89-93, 2017.

13- NOLLER M.W., BAUGHMAN S.M., MOREY A.F. and AUGE B.K.: Fibrin sealant enables tubeless percutaneous stone surgery. J. Urol., 172 (1): 166-9, 2004.

14- YU D.S.: Gelatin packing of intracortical tract after percutaneous nephrostomy lithotripsy for decreasing bleeding and urine leakage. J. Chin. Med. Assoc., 69 (4): 162-5, 2006.

15- SINGH P. and MANDHANI A.: Use of absorbable gelatin sponge as an adjunct to" totally tubeless percutaneous nephrolithotomy. Arch. Esp. Urol., 62 (6): 423-9, 2009.

16- DAYAPULE S., VADDI S., BHASKAR G.V. and PATHAPATI R.: Efficacy and Safety of Tubeless Percutaneous Nephrolithotomy versus Standard Percutaneous Nephrolithotomy. I.J.S.S. Surgery, 2 (4): 16-20, 2016.

17- LIPKIN M.E., MANCINI J.G., SIMMONS W.N., RAYMUNDO M.E., YONG D.Z., WANG A.J., et al.: Pathologic evaluation of hemostatic agents in percutaneous nephrolithotomy tracts in a porcine model. J. Endourol., 25 (8): 1353-7, 2011.

18- LEE D.I., URIBE C., EICHEL L., KHONSARI S., BASILLOTE J., PARK H.K., et al.: Sealing percutaneous nephrolithotomy tracts with gelatin matrix hemostatic sealant: Initial clinical use. J. Urol., 171 (2): 575-8, 2004.

19- BORIN J.F., SALA L.G., EICHEL L., McDOUGALL E.M. and CLAYMAN R.V.: Tubeless percutaneous nephrolithotomy using hemostatic gelatin matrix. J. Endourol., 19 (6): 614-7, 2005.

20- EVANS L.A., FERGUSON K.H., FOLEY J.P., ROZANSKI T.A. and MOREY A.F.: Fibrin sealant for the management of genitourinary injuries, fistulas and surgical complications. J. Urol., 169 (4): 1360-2, 2003.

21- CORMIO L., PERRONE A., Di FINO G., RUOCCO N., De SIATI M., De La ROSETTE J., et al.: Tachosil® sealed tubeless percutaneous nephrolithotomy to reduce urine leakage and bleeding: Outcome of a randomized controlled study. J. Urol., 188 (1): 145-50, 2012.

22- HONG Y.M. and LOUGHLIN K.R.: The use of hemostatic agents and sealants in urology. J. Urol., 176 (6): 236774, 2006.

23- JOU Y.C., LU C.L., CHEN F.H., SHEN C.H., CHENG M.C., LIN S.H., et al.: Contributing factors for fever after tubeless percutaneous nephrolithotomy. Urology, 85 (3): 527-30, 2015.

24- AGHAMIR S., KHAZAELI M. and MEISAMI A.: Use of Surgicel for sealing nephrostomy tract after totally tubeless percutaneous nephrolithotomy. J. Endourol., 20 (5): 293-5, 2006.

25- PATEL R., CARUSO R.P., TANEJA S. and STIFELMAN M.: Use of fibrin glue and gelfoam to repair collecting system injuries in a porcine model: Implications for the technique of laparoscopic partial nephrectomy. J. Endourol., 17 (9): 799-804, 2003.

26- GABAY M. and BOUCHER B.A.: An essential primer for understanding the role of topical hemostats, surgical sealants, and adhesives for maintaining hemostasis. Pharmacotherapy, 33 (9): 935-55, 2013.

27- GOODNOUGH L.T., BODNER M.S. and MARTIN J.W.: Blood transfusion and blood conservation: Cost and utilization issues. Am. J. Med. Qual., 9 (4): 172-83, 1994.

28- SHANDER A., HOFMANN A., OZAWA S., THEUSINGER O.M., GOMBOTZ H. and SPAHN D.R.: Activitybased costs of blood transfusions in surgical patients at four hospitals. Transfusion, 50 (4): 753-65, 2010.

29- STOKES M.E., YE X., SHAH M., MERCALDI K., REYNOLDS M.W., RUPNOW M.F., et al.: Impact of bleedingrelated complications and/or blood product transfusions on hospital costs in inpatient surgical patients. B.M.C. Health Services Research, 11 (1): 135, 2011. 


\section{دراسة إستخدام موقفات النزف الموضعية لغلق مجرى منظار الكلى}

المقدمة: منظار الكلى هو الطريقة المفضلة لعلاج الحصوات الموجودة بالكلى والتى يزيد حجمها عن كسم مع تركيب آنبوبة كلوية بعد العملية من آجل وقف النزيف والتصريف ولنظرة ثانية.

حديثا يوجد إتجاه إلى عدم تركيب آنبوبة الكلى بعد المنظار وذلك لتقليل الآلم بعد العملية، الإحتياج للمسيكنات والإقامة بالمستشفى. الكثير من الدراسات تنصح بإستخدام موقفات النزف الموضعية بعد منظار الكلى وذلك لتقليل النزف والتسرب البولى. الهدف من البحث: دراسة إستخدام موقفات النزف الموضعية لغلق مجرى منظار الكلى.

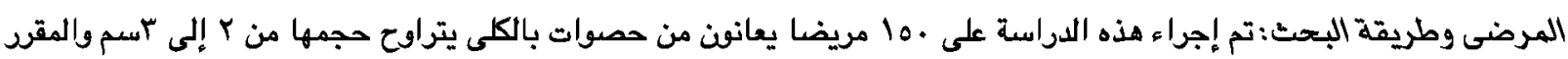

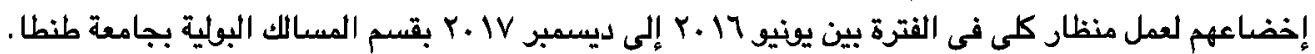

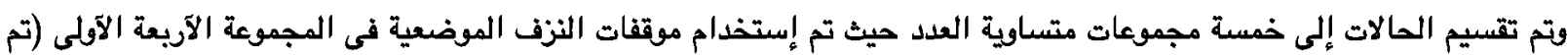

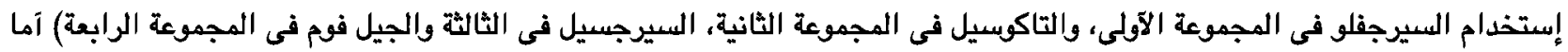
المجموعة الخامسة تم تركيب آنبوبة كلوية.

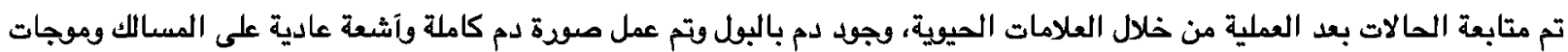

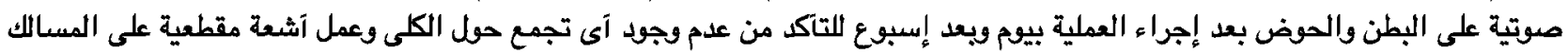

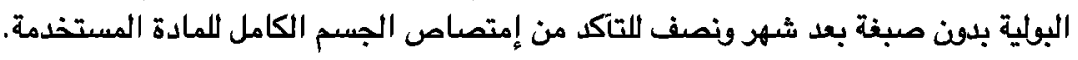

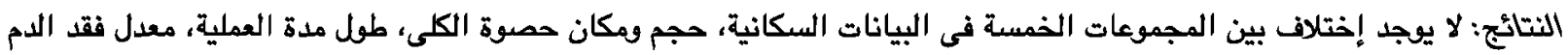

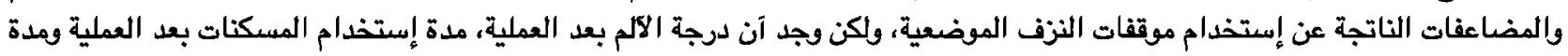

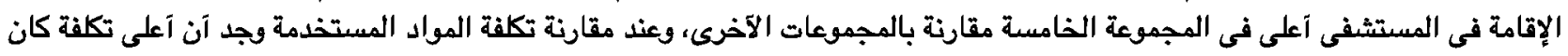
في المجموعة الثانية.

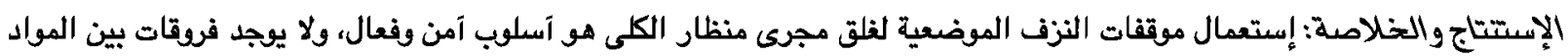

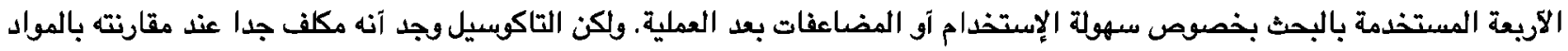

